\title{
ESTUDO DA QUALIDADE DA ÁGUA DO CÓRREGO DA CASCATA E/OU TABUINHA DE PRESIDENTE PRUDENTE.
}

\section{STUDY OD THE QUALITY OF THE CASCATAS AND/OR TABUINHA STREAM OF PRESIDENTE PRUDENTE.}

\author{
Carolina Gomes de Melo ${ }^{1}$; Danielle Elis Garcia Furuya ${ }^{1}$; Ireli Cristina Luz ${ }^{1}$; \\ Lucas Flávio Thomaz'; Nayara de Jesus Figueiredo'; Elson Mendonça Felici². \\ Universidade do Oeste Paulista - UNOESTE, Curso de Engenharia Ambiental e Sanitária, \\ Presidente Prudente, SP. \\ E-mail: daniellegarciafuruya@gmail.com
}

RESUMO - A conservação dos cursos d'água são essenciais pois possibilitam a realização de atividades que necessitam desse recurso natural e determinam as características da microbacia em que estão inseridos. $O$ crescimento populacional acelerado exige o aumento da utilização dos recursos naturais, como por exemplo a água presente nos córregos. Além da utilização, o tratamento incorreto e os impactos ambientais vêm diminuindo cada vez mais a disponibilidade hídrica dos rios e afluentes em cada bacia hidrográfica. A microbacia do Córrego da Cascata e/ou Tabuinha apresenta indícios de degradação ambiental, visto que a profundidade e quantidade da água no córrego se apresenta escassa. Nesse contexto, o objetivo desse estudo foi analisar parâmetros que determinam a qualidade da água do córrego, bem como realizar visitas ao local, coleta e análise das amostras e verificação dos resultados.

Palavras-chave: Análises, córrego, parâmetros de água.

ABSTRACT - The conservation of the watercourses are essential because they enable the accomplishment of activities that need this natural resource and determine the characteristics of the microbasin in which they are inserted. Rapid population growth requires increased use of natural resources, such as water in streams. In addition to the use, incorrect treatment and environmental impacts are increasingly decreasing the water availability of rivers and tributaries in each river basin. The microcatchment of the Cascata stream and / or Tabuinha shows signs of environmental degradation, since the depth and quantity of water in the stream is scarce. In this context, the objective of this study was to analyze parameters that determine the water quality of the stream, as well as to analyze the interference of a tannery.

Keywords: Analysis, stream, parameters. 


\section{INTRODUÇÃO}

A conservação de córregos e rios têm se tornado uma questão preocupante devido ao aumento da urbanização e consequentemente dos impactos que afetam diretamente os corpos d'água.

A forma como se dá a ocupação urbana provoca várias alterações no espaço que influem diretamente no meio ambiente, gerando desequilíbrios que atingem aos recursos hídricos, já a partir de suas nascentes. Apesar de a legislação determinar que as nascentes sejam preservadas e que não se ocupem (e se preservem, preferencialmente com vegetação nativa) um raio de pelo menos 50 metros, em muitos locais a preservação das nascentes não tem se concretizado, pois a configuração do modelo urbano de desenvolvimento leva à ocupação de suas áreas, ao aterramento e à drenagem, entre outros fatores, alterando toda a dinâmica fluvial (BELIZÁRIO, 2015).

A bacia hidrográfica tem sido utilizada como uma unidade geomorfológica fundamental da superfície terrestre, suas características governam, todo o fluxo superficial da água e, com isso, pode ser considerada como uma unidade de trabalho quando se deseja a preservação dos recursos hídricos, pois as atividades desenvolvidas no seu interior têm influência sobre a quantidade e qualidade da água (FERNANDES, 2012).

Nesse aspecto, segundo BELIZÁRIO, 2015 "há uma série de elementos que vão contribuir negativamente para a qualidade ambiental nas bacias hidrográficas, tais como: o lançamento de efluentes domésticos; o lançamento de efluentes diretamente nos cursos d'água por parte de indústrias; residências e empresas (públicas e privadas) construídas fora dos limites de proteção estabelecidos por lei; retirada da cobertura vegetal (com desmatamento e diminuição da mata ciliar); assoreamento; erosões; resíduos da criação de animais; entre outros."

A microbacia do Córrego da Cascata e/ou Tabuinha está localizada no município de Presidente Prudente, com extensão de 3,36 $\mathrm{Km}^{2}$. A microbacia é composta por um curtume, sendo que há somente uma pequena porção urbana, ou seja, a área rural prevalece na extensão da microbacia.

Nesse contexto, o objetivo deste estudo foi verificar a qualidade da água do córrego da Cascata e/ou Tabuinha através da análise de alguns parâmetros.

\section{METODOLOGIA}

$\mathrm{O}$ estudo foi realizado com a finalidade de identificar a atual situação da qualidade da água do córrego da Cascata e/ou Tabuinha, levando em consideração alguns fatores que interferem nas condições do córrego.

O córrego da Cascata e/ou Tabuinha localiza-se próximo ao Parque Furquim de Presidente Prudente. A Figura 1 mostra a delimitação da microbacia do córrego em estudo.

Figura 1. Delimitação da microbacia do córrego da Cascata e/ou Tabuinha

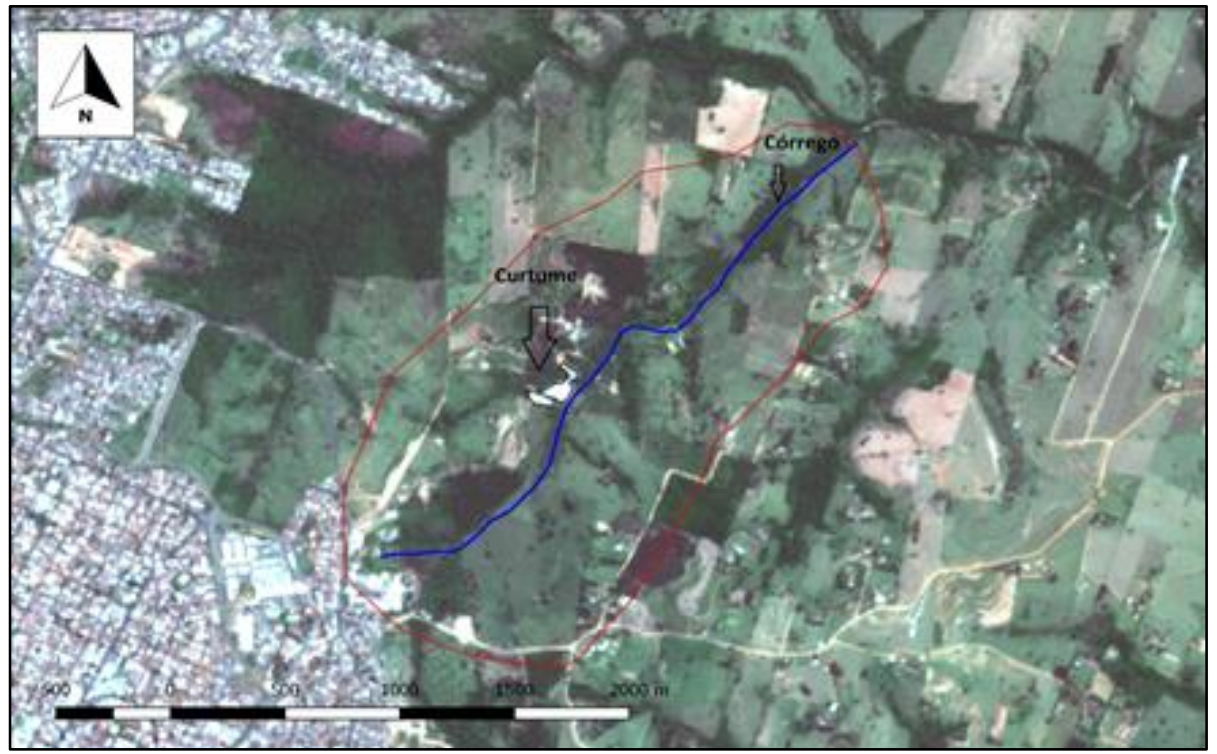

Fonte: Autores, 2017. Adaptado: QGIS, imagem sentinela-2, 2017. 
O estudo da qualidade da água do Córrego da Cascata e/ou Tabuinha foi realizado em 5 etapas subdivididas 5 etapas: conforme o fluxograma (Figura 2).

Figura 2. Etapas para estudo da qualidade da água.

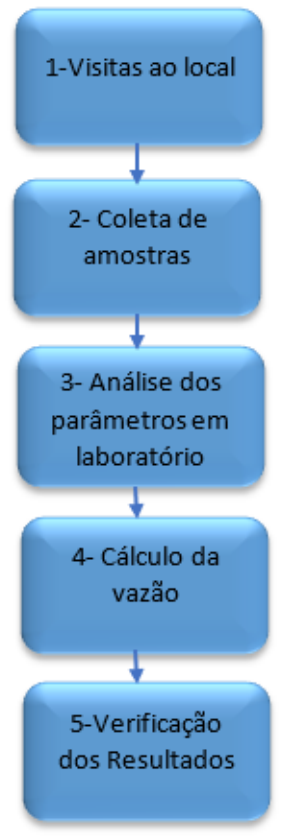

Fonte: Autores (2018).

Figura 3. Pontos de coleta de amostras para análise.

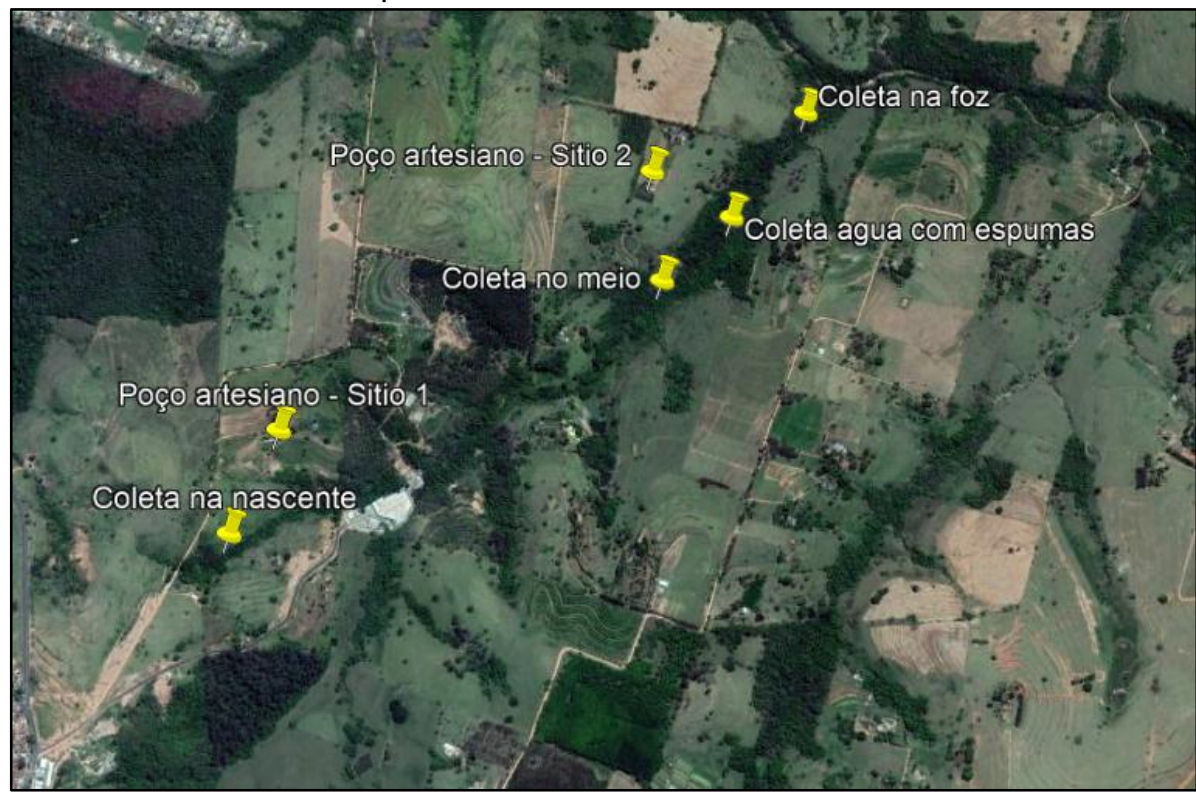

Fonte: Autores, 2017. Adaptado Google Maps, 2017.

\subsection{Análise dos parâmetros em laboratório}

As amostras coletadas foram transportadas até o laboratório de Química da Universidade do Oeste Paulista onde foram analisados os parâmetros $\mathrm{pH}$, temperatura, turbidez, fósforo e Demanda Química de Oxigênio (DQO), atendendo as normas de Standard Methods for The Examination of Water

\subsection{Visitas ao local}

Foram realizadas duas visitas ao córrego antes de coletar as amostras com o intuito de conhecer a área de estudo, através da coleta de dados e registro fotográfico.

\subsection{Coleta de amostras}

A coleta das amostras foi realizada no dia 16 de Outubro de 2017. Foram estudados e definidos 6 pontos de coleta envolvendo os recursos hídricos da microbacia como mostrado na Figura 3, sendo quatro pontos ao longo do córrego e dois poços artesianos próximos ao curso d'água. 
As análises foram realizadas com a utilização dos aparelhos pHmetro, turbidímetro e espectofotômetro. Cada parâmetro seguiu o método descrito na Figura 4 .

Figura 4. Métodos utilizados nas análises dos parâmetros.

$$
\begin{aligned}
& \text { Ph } \rightarrow \text { Método potenciométrico - SMWW, 21a Edição, Método 4500 - H+2; } \\
& \text { Turbidez (unt) } \rightarrow \text { Método nefelométrico - MWW, 21 a Edição, Método } 2130 \text { - B; } \\
& \text { Fósforo } \rightarrow \text { Redução com Ácido Ascórbico - SMWW, 21a Edição, Método } 4500 \text { - P.F; } \\
& D Q 0 \rightarrow \text { Método do refluxo fechado - SMWW, 21a Edição, Método } 5220 \text { C; } \\
& \text { Coliformes fecais } \rightarrow \text { Método dos tubos múltiplos e membrana filtrante - CETESB, norma }
\end{aligned}
$$

Fonte: Autores, 2017.

\subsection{Cálculo da vazão}

Para encontrar as medidas necessárias para o cálculo da vazão do córrego utilizou-se um vertedor triangular como mostra a Figura 5.
Figura 5. Vertedor triangular para o cálculo da vazão

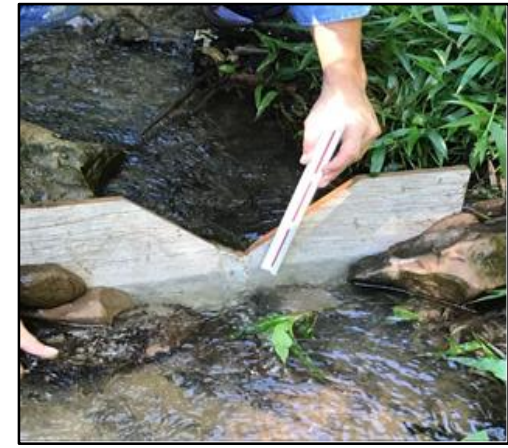

Fonte: Autores, 2017.

\subsection{Verificação dos resultados}

O cálculo das análises de fósforo e DQO foram realizados com base nas curvas de calibração mostradas nos Gráficos 1 e 2. Nas equações das curvas, o y foi substituído pelos valores encontrados para cada ponto. O resultado final corresponde ao valor $\mathrm{x}$ da equação.

Figuras 6 e 7. Curvas de calibração de fósforo e DQO respectivamente.

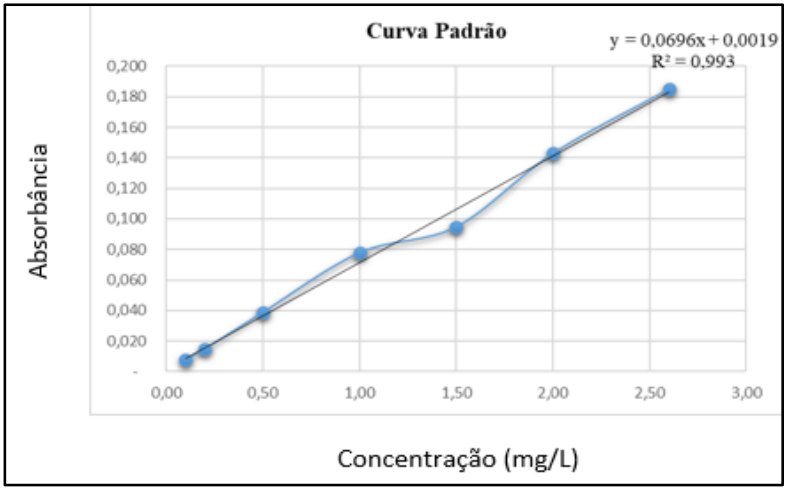

Fonte: Autores (2017).

\section{RESULTADOS}

Durante as primeiras visitas ao Córrego da Cascata foram registrados alguns pontos para realizar a coleta de amostras de água e elaboradas as características de cada ponto.

\subsection{Características dos pontos}

As amostras foram coletadas nos pontos estabelecidos (Figura 3). Foram identificadas as características correspondentes aos pontos selecionados.

\subsubsection{Ponto 1}

O ponto 1 corresponde as coordenadas 22 $10^{\prime} 55^{\prime \prime} \mathrm{S} ; 51036^{\prime} 85^{\prime \prime} \mathrm{W}$. Representa a

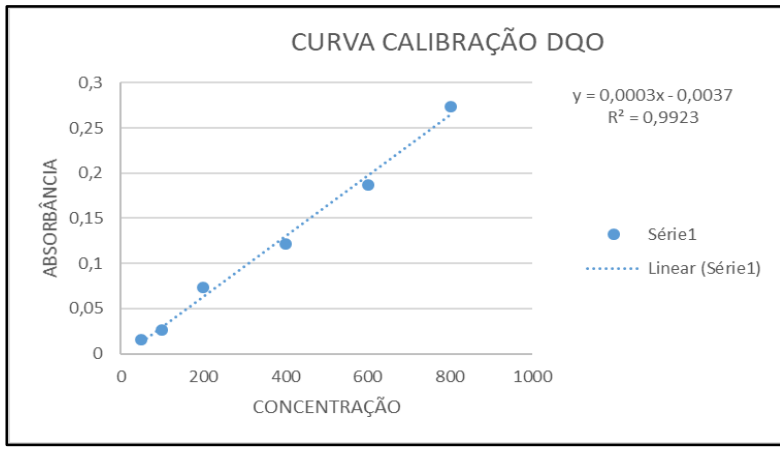

principal nascente do córrego, a montante do curtume.

\subsubsection{Ponto 2}

O ponto 2 corresponde as coordenadas 22 10' 06" S; 51은 35' 94" W. Representa o ponto central do córrego, a jusante do curtume.

\subsubsection{Ponto 3}

O ponto 3 corresponde as coordenadas 22ㅇ 09' 83" S; 51ㅇ 35' 79" W. Representa um ponto a jusante do curtume, a coleta foi realizada devido a presença de espuma no córrego. 


\subsubsection{Ponto 4}

O ponto 4 corresponde as coordenadas $22 \circ 09^{\prime} 44^{\prime \prime}$ S; 51은 35' 37"W. Representa a foz do córrego.

\subsubsection{Ponto 5}

O ponto 5 corresponde as coordenadas 22 10' 25" S; 51 $36^{\prime} 73^{\prime \prime}$ W. Representa o poço artesiano do sítio 1 , localizado a montante do curtume.

\subsubsection{Ponto 6}

0 ponto 6 corresponde as coordenadas 22ㅇ 09' 67" S; 51 $35^{\prime} 90^{\prime \prime} \mathrm{W}$. Representa o poço artesiano do sítio 2, localizado a jusante do curtume.

\subsection{Parâmetros}

A Tabela 1 mostra os resultados dos parâmetros obtidos nas análises em laboratório.

Tabela 1. Resultados dos parâmetros de cada ponto.

\begin{tabular}{|c|c|c|c|c|c|l|}
\hline Parâmetro & $\begin{array}{c}\text { Ponto } \\
\mathbf{1}\end{array}$ & $\begin{array}{c}\text { Ponto } \\
\mathbf{2}\end{array}$ & $\begin{array}{c}\text { Ponto } \\
\mathbf{3}\end{array}$ & $\begin{array}{c}\text { Ponto } \\
\mathbf{4}\end{array}$ & Ponto 5 & Ponto 6 \\
\hline pH & 6,59 & 7,55 & 6,99 & 7,86 & 6,91 & \\
\hline Temperatura $\left({ }^{\circ} \mathrm{C}\right)$ & 15,1 & 14,1 & 14,9 & 16,2 & 15,7 & \\
\hline Turbidez & 2,50 & 2,96 & 17,2 & 8,57 & 0,08 & \\
\hline Fósforo & 0,3606 & 0,1882 & 1,6968 & 1,1508 & 1,1652 & \\
\hline DQO (mg/L) & 145,66 & 545,66 & 445,66 & 345,66 & 245,66 & \\
\hline Coliformes Fecais & & & & & Negativo & Negativo \\
\hline
\end{tabular}

Fonte: Autores(2017).

A vazão foi calculada de acordo com as medições em campo com o auxílio do vertedor triangular. $\mathrm{O}$ vertedor foi apoiado no fundo e nas laterais do canal do córrego. Com o auxílio de rochas a jusante e sacos de areia a montante do vertedor, garantiu-se a estabilidade da placa. Para a medição da carga hidráulica (h) utilizou-se um escalímetro, conforme a Figura 5. Após o período de medição em campo, foi realizada a leitura da altura da lâmina d'água no vertedor. A equação utilizada para determinar a vazão no vertedor foi a equação de Thonson, dada por: $\mathrm{Q}=1,4 \cdot \mathrm{H}^{\wedge}(5 / 2)$

Seguindo o método, verificou-se que o resultado da vazão do Córrego da Cascata e/ou Tabuinha corresponde a $0,6 \mathrm{~L} / \mathrm{s}$, conforme os cálculos mostrados a seguir:
$\mathrm{Q}=1,4 \cdot \mathrm{H}^{\wedge}(5 / 2)$ 回 $\mathrm{Q}=1,4 \cdot \llbracket 0,045 \rrbracket \wedge(5 / 2)$ ? $\square$

$\mathrm{Q}=6,01 \times 10 \rrbracket \wedge(-4) \mathrm{m}^{3} / \mathrm{s}$ 回 $\mathrm{Q}=0,0006 \mathrm{~m}^{3} / \mathrm{s}$

$\mathrm{Q}=0,6 \mathrm{~L} / \mathrm{s}$

\section{DISCUSSÃO}

Através dos resultados obtidos foi possível observar alterações no curso d'água, o córrego da Cascata e/ou Tabuinha deságua no rio Mandaguari, que deságua em um dos rios responsáveis pelo abastecimento da cidade. O córrego da Cascata corresponde a um corpo d'água de classe 3 segundo a Resolução CONAMA n ${ }^{\circ} 357$, ou seja, água doce que pode ser destinada ao abastecimento para consumo humano após tratamento convencional ou avançado, à irrigação de culturas arbóreas, cerealíferas e forrageiras, à pesca amadora, à recreação de contato secundário e à dessedentação de animais.

Através das visitas ao local, pesquisas bibliográficas e do cálculo da vazão verificou-se que o Córrego da Cascata e/ou Tabuinha possui extensão de 2,29 Km e corresponde a um curso d'água lêntico, a profundidade do córrego não ultrapassa 1 metro durante todo o percurso, indicando ocorrência de assoreamento e degradação do curso d'água. O curtume está localizado próximo a nascente (ponto 1), sendo que a profundidade nesse ponto não ultrapassa $15 \mathrm{~cm}$.

Segundo Pereira e Lima, 2007, em um estudo sobre a contaminação hídrica por fluidos provenientes de um curtume, os parâmetros analisados apresentaram alterações, inclusive do metal pesado cromo, mostrando que os resíduos provenientes do curtume causaram contaminação no recurso hídrico de estudo.

Em uma pesquisa feita por Muller, 2016 em um rio localizado próximo a um curtume, as análises de $\mathrm{pH}$ mostraram que não ocorreram mudanças nos pontos a montante e a jusante, os valores de $\mathrm{pH}$ se aproximaram da neutralidade. A turbidez foi maior nos pontos à montante do que nos pontos à jusante.

\section{CONCLUSÃO}

A qualidade da água do Córrego da Cascata e/ou Tabuinha vêm sendo afetada e agravada conforme registros fotográficos que mostram a baixa profundidade e consequentemente a baixa quantidade de água que compõe o córrego. Análises de metais pesados e outros parâmetros são necessários para entender se o resíduo encontrado no córrego (espuma) provém do lançamento do estabelecimento. 


\section{REFERÊNCIAS}

ABNT. NBR 9897. Planejamento de amostragem de efluentes líquidos e corpos receptores. 1987.

APHA. Standard Methods for the Examination of Water and Wastewater. 22 ed. Washington, 2012.

BELIZÁRIO, W.S. Avaliação da Qualidade Ambiental de Nascentes em Áreas Urbanas: um Estudo sobre Bacias Hidrográficas do Município de Aparecida de Goiânia/GO. Revista Mirante, Anápolis (GO), v. 8, n. 1, jun. 2015.

BRASIL. Lei $n^{\circ} 9.433$ de 08 de janeiro de 1987. Institui a Política Nacional de Recursos Hídricos. Disponível em:

http://www.planalto.gov.br/ccivil_03/leis/L9433. htm>. Acesso em 18 de novembro de 2017.

CONAMA. Resolução $\mathbf{n}$ 357, de 17 de março de 2005.

FERNANDES, M.M. et.al. Influência do uso do solo na qualidade de água da microbacia Palmital, Macaé - RJ. Revista Verde de Agroecologia e Desenvolvimento Sustentável, v. 7, n. 3 (2012).

MULLER, T. et.al. Qualidade da água de três locais com potenciais fontes de contaminação no Rio Taquari, RS. Revista Ambiental Água vol. 11 n. 1 Taubaté - Jan. / Mar. 2016

NORMA TECNICA, L5202 Coliformes totais e fecais - determinação pela técnica de tubos múltiplos: método de ensaio, 1993.

PEREIRA, P.A e LIMA, O.A.L. Estrutura elétrica da contaminação hídrica provocada por fluidos provenientes dos depósitos de lixo urbano e de um curtume no município de alagoinhas, Bahia. Revista Brasileira de Geofísica (2007) 25(1): 5-19 (C) 2007 Sociedade Brasileira de Geofísica.

RIBEIRO, M.A, Vazão, Fundamentos e Aplicações 5a Edição Marco Antônio Ribeiro 1991.

SILVA, A. M. Princípios Básicos de Hidrologia. Departamento de Engenharia. UFLA. Lavras-MG. 1995.
SP. Lei no 7.663, de 30 de dezembro de 1991. Política Estadual de Recursos Hídricos. 1991. Disponível em:

https://www.al.sp.gov.br/repositorio/legislacao/I ei/1991/lei-7663-30.12.1991.html>. Acesso em 19 de novembro de 2017. 